\title{
pH/GSH-dual-sensitive hollow mesoporous silica nanoparticle-based drug delivery system for targeted cancer therapy
}

Zhongyin Chen, ${ }^{\mathrm{a}, 1}$ Lihui Wan, ${ }^{\mathrm{a}, 1}$ Ye Yuan, ${ }^{\mathrm{b}}$ Ying Kuang, ${ }^{\mathrm{c}}$ Xiangyu Xu, ${ }^{\mathrm{a}}$ Tao Liao, ${ }^{\mathrm{a}} \mathrm{Jia}$

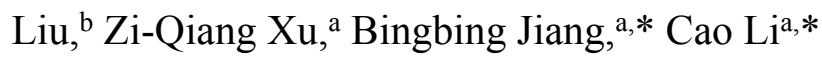

a. Ministry-of-Education Key Laboratory for the Green Preparation and Application of Functional Materials. Hubei Key Laboratory of Polymer Materials. Hubei University. Wuhan 430062, China.

b. Research Center for Tissue Engineering and Regenerative Medicine, Union Hospital, Tongji Medical College, Huazhong University of Science and Technology, Wuhan, Hubei 430022, China.

c. Glyn O. Philips Hydrocolloid Research Centre at HUT, Hubei University of Technology. Wuhan, Hubei 430068, China.

*Corresponding author: E-mail: bingbingjiang@hubu.edu.cn (B. Jiang); licao0415@163.com (C. Li)

${ }^{1}$ Z. Chen and L. Wan contributed equally to this work. 
Synthesis of p-toluenesulfonyl- $\beta$-cyclodextrin ( $\beta$-CD-OTs)

$10.0 \mathrm{~g}$ of $\beta$-CD was dissolved in $240 \mathrm{~mL}$ of deionized (DI) water under stirring. Later, $2.6 \mathrm{~g}$ of $p$-TsCl was added at a very low rate $(1 / 3 \mathrm{~mL} / \mathrm{min})$ to ensure that the substitution occurred at the C6 position. After vigorous agitation for $3 \mathrm{~h}$ at room temperature, $40 \mathrm{~mL}$ of $\mathrm{NaOH}$ solution $(2.5 \mathrm{M})$ was dropped. The obtained suspension was filtered, and $12.0 \mathrm{~g}$ of $\mathrm{NH}_{4} \mathrm{Cl}$ was added to the filtrate solution until its $\mathrm{pH}$ was adjusted to 8 . The resultant solution was cooled to $\sim 4{ }^{\circ} \mathrm{C}$ and kept overnight. The precipitation was collected by vacuum filtration and washed by acetone three times. Finally, to remove unreacted $p$-TsCl and $\beta$-CDs, the crude product was recrystallized at $60{ }^{\circ} \mathrm{C}$ for three times. After being dried under vacuum at $50{ }^{\circ} \mathrm{C}$ for $48 \mathrm{~h}, \beta$-CD-OTs was obtained.

Synthesis of S-(2-aminoethylthio)-2-thiopyridine hydrochloride

$4.41 \mathrm{~g}$ of thiopyridyl disulfide $(20.0 \mathrm{mmol})$ was dissolved in $20 \mathrm{~mL}$ of methanol with $0.8 \mathrm{~mL}$ of acetic acid. Then $1.14 \mathrm{~g}$ of cysteamine hydrochloride (10.0 mmol) was dissolved in $10 \mathrm{~mL}$ of methanol and was added dropwise to the thiopyridyl disulfide solution over a period of $0.5 \mathrm{~h}$. The reaction was taken at room temperature for $48 \mathrm{~h}$ and then evaporated under vacuum to obtain yellow oil. The oil was washed with 50 $\mathrm{mL}$ of diethyl ether and was dissolved in $10 \mathrm{~mL}$ of methanol. The product was precipitated through $200 \mathrm{~mL}$ of cold diethyl ether twice to obtain a yellow solid.

Synthesis of adamantine blocked Poly-L-lysine (PLL-Ad)

$3.1 \mathrm{~g}$ of $\mathrm{H}-(\mathrm{z}) \mathrm{Lys}-\mathrm{OH}$ and $1.7 \mathrm{~g}$ of triphosgene were dissolved in $60 \mathrm{~mL}$ of THF, and the mixture was stirred at $50{ }^{\circ} \mathrm{C}$ under $\mathrm{N}_{2}$ atmosphere for $4 \mathrm{~h}$. The solution was 
precipitated in excess dried petroleum ether for three times to obtain L-NCA and recrystallized from dried THF/n-hexane twice. $900 \mathrm{mg}$ of L-NCA and $50 \mathrm{mg}$ of 1-adamantylamine were dissolved in $40 \mathrm{~mL}$ of dried DMF. The reaction was carried out at $40{ }^{\circ} \mathrm{C}$ under $\mathrm{N}_{2}$ atmosphere for $72 \mathrm{~h}$. Then the reaction mixture was precipitated three times in an excess of diethyl ether and dried in vacuum to give PzLAd. $600 \mathrm{mg}$ of PzLL-Ad was dissolved in $35 \mathrm{~mL}$ of TFA. After $15 \mathrm{~min}$ stirring, $4 \mathrm{~mL}$ of $\mathrm{HBr}$ (33 $\mathrm{wt} \%$ solution in acetic acid) was added dropwise and the system was stirred for $1 \mathrm{~h}$ in the ice bath. The crude reaction product was precipitated from anhydrous diethyl ether. After drying, the product was suspended in DMF, and the solution was placed in a dialysis bag (molecular weight cut off $(\mathrm{MWCO})=3500 \mathrm{Da})$ and dialyzed against DI water for 3 days (water changed every $8 \mathrm{~h}$ ). After dialysis, the sample was lyophilized to give PLL. 


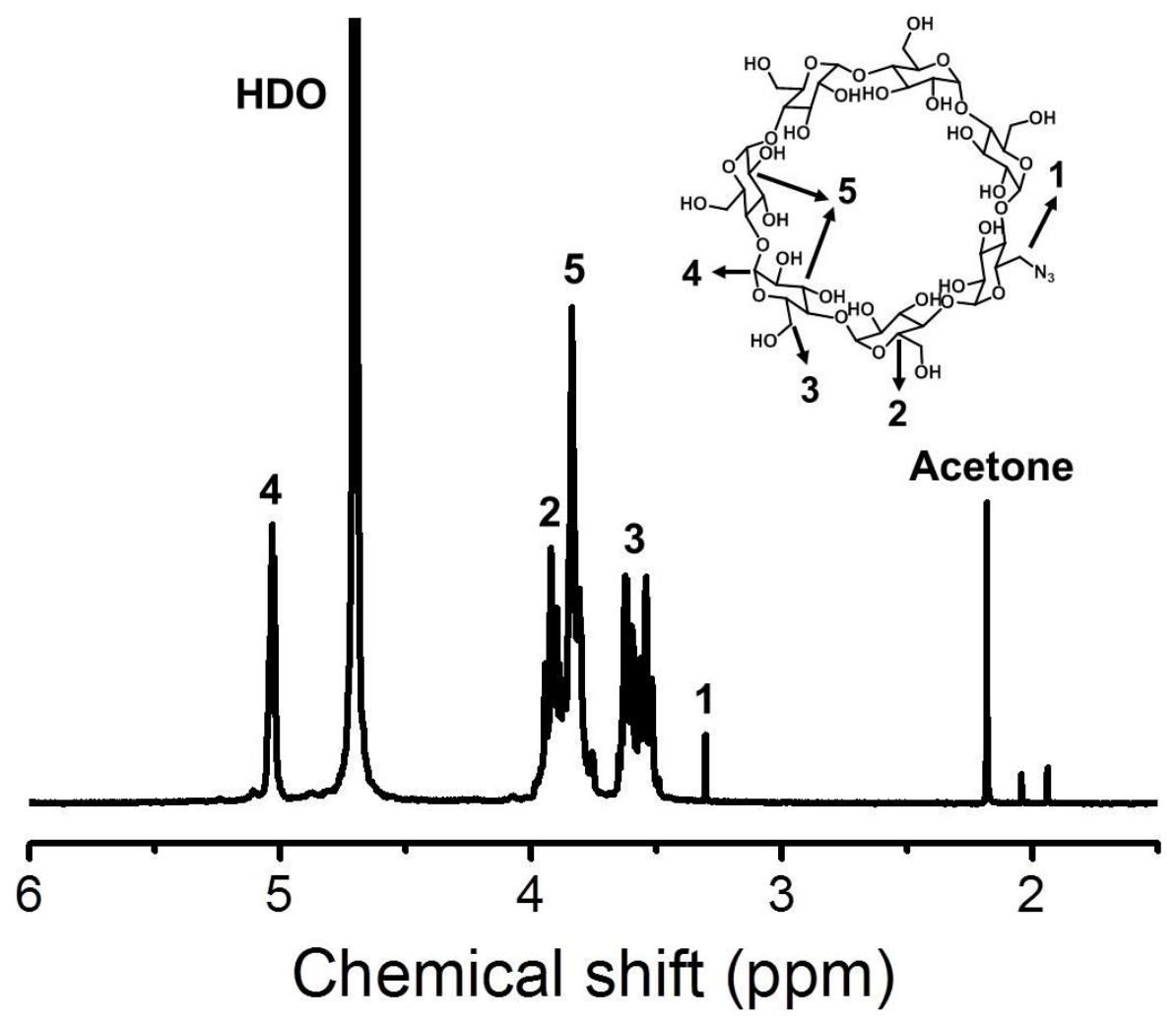

Figure S1 The ${ }^{1} \mathrm{H}$ NMR spectrum of $\beta-\mathrm{CD}-\mathrm{N}_{3}$. 


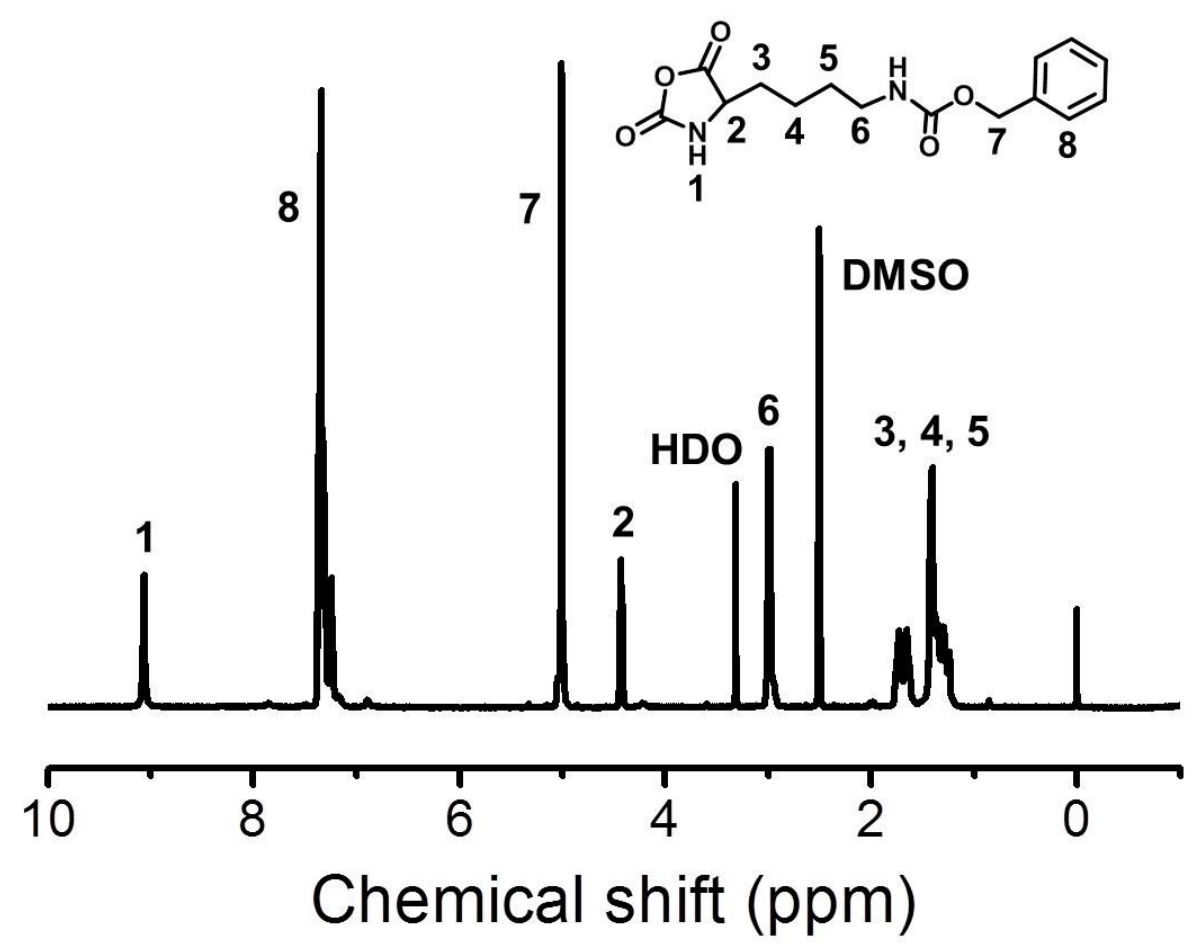

Figure S2 The ${ }^{1} \mathrm{H}$ NMR spectrum of L-NCA. 


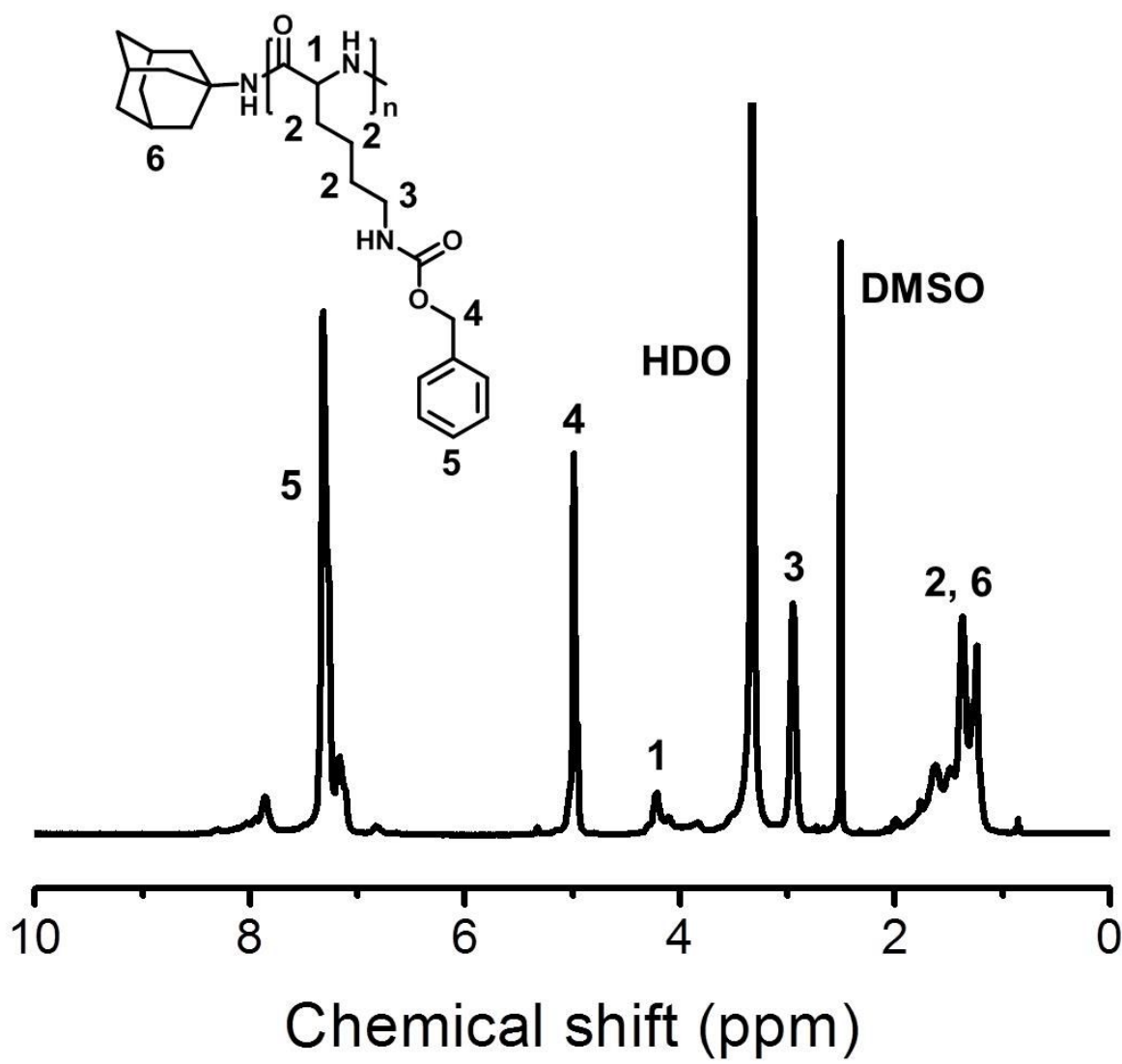

Figure S3 The ${ }^{1} \mathrm{H}$ NMR spectrum of PzLL-Ad. 


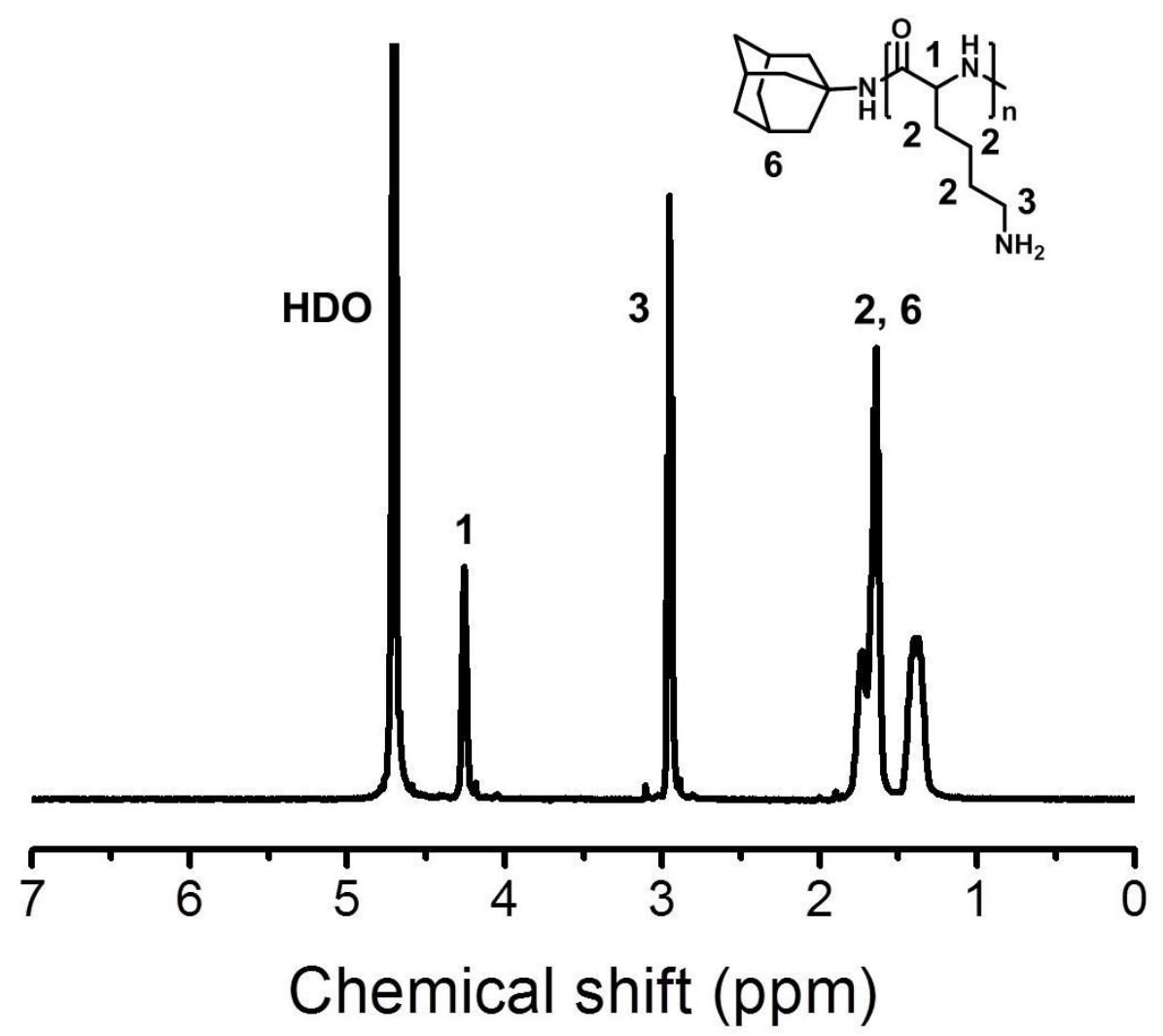

Figure S4 The ${ }^{1} \mathrm{H}$ NMR spectrum of PLL-Ad. 


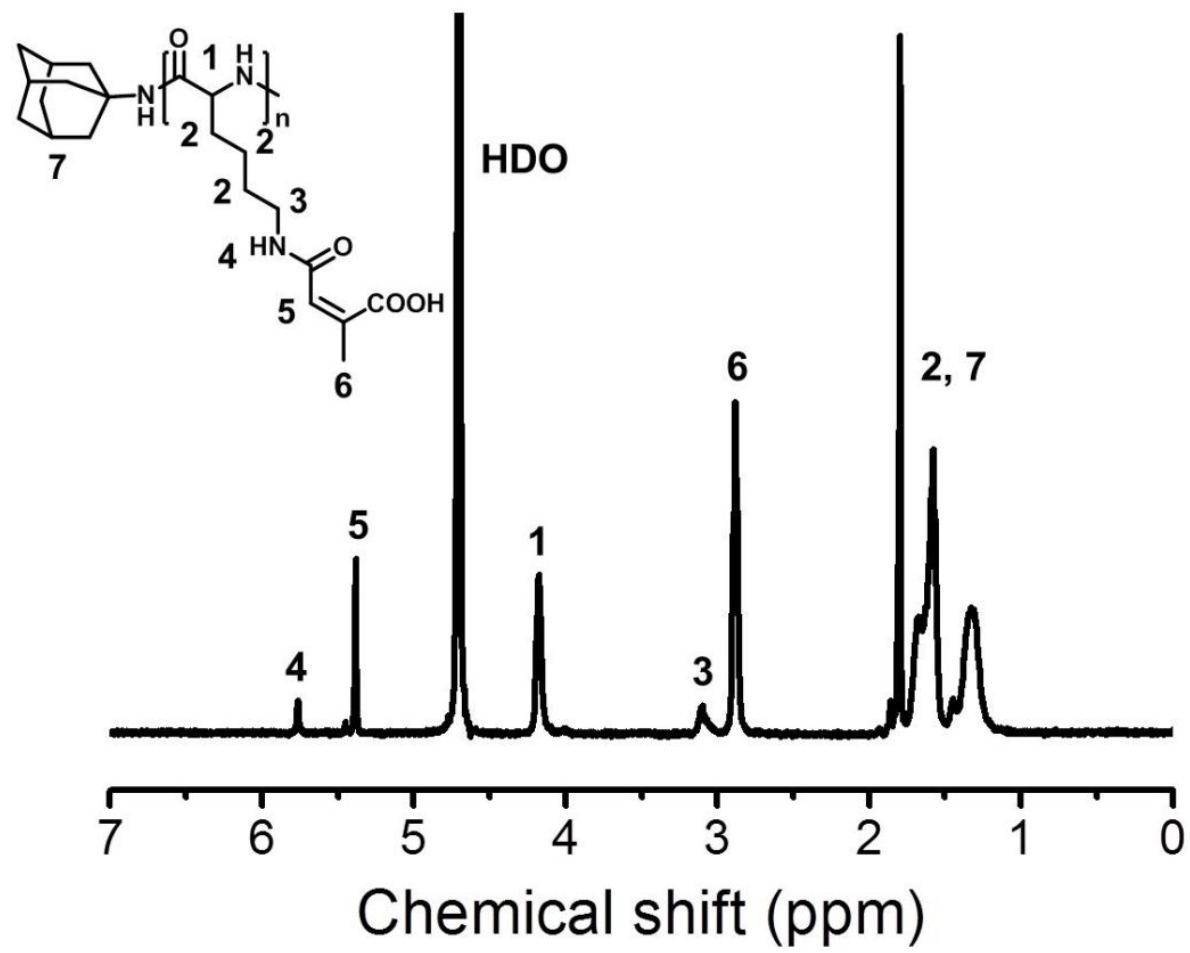

Figure S5 The ${ }^{1} \mathrm{H}$ NMR spectrum of PLL(cit)-Ad. 


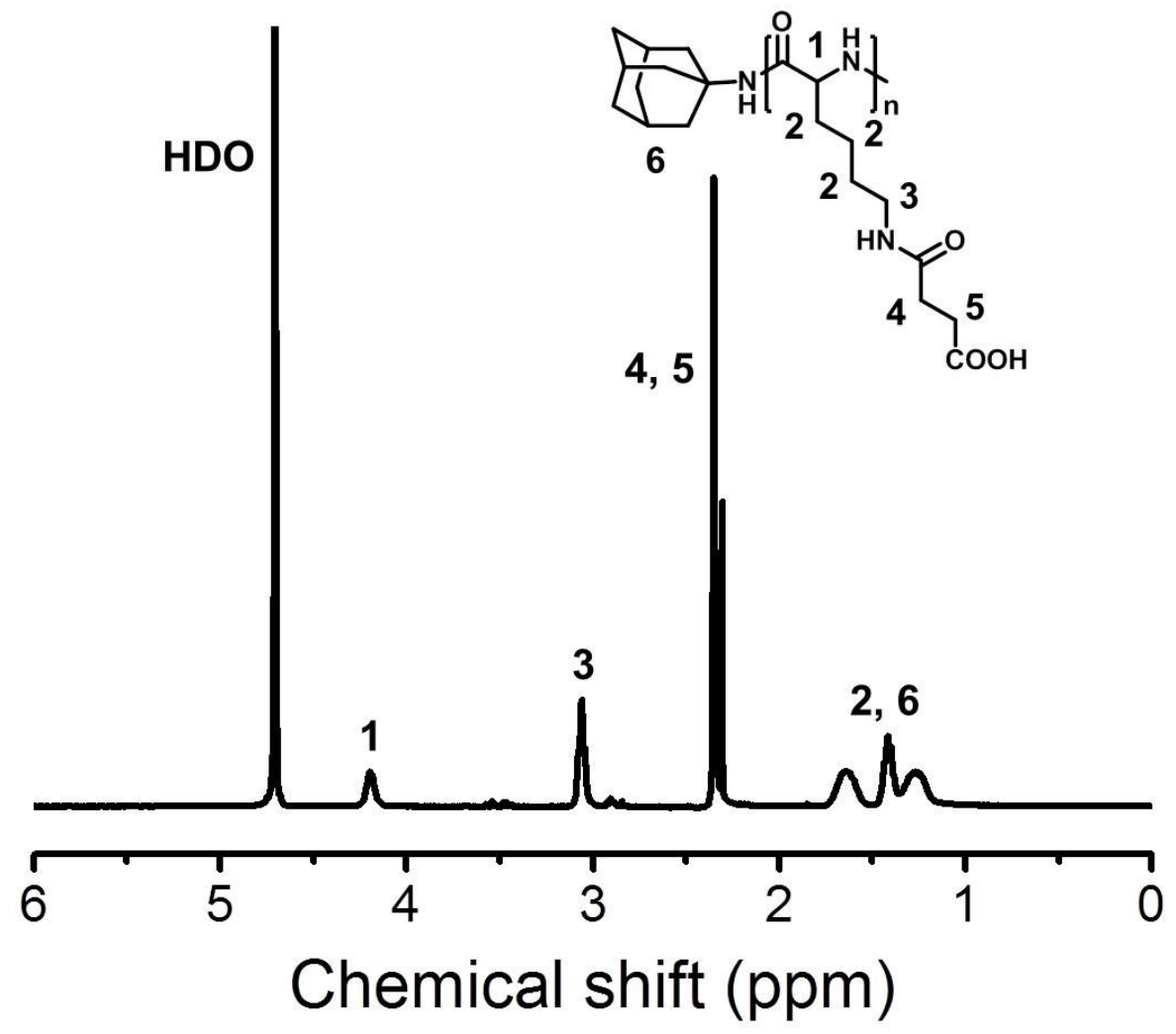

Figure S6 The ${ }^{1} \mathrm{H}$ NMR spectrum of PLL(sa)-Ad. 

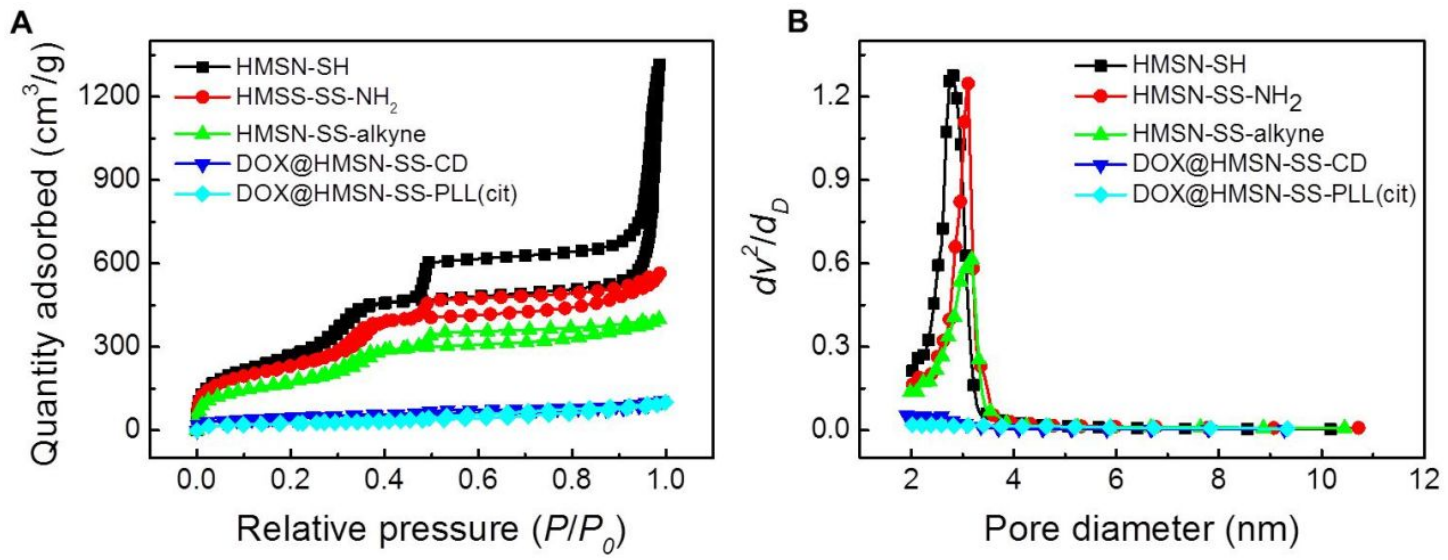

Figure S7 Nitrogen adsorption-desorption isotherms (A) and BJH pore distributions (B) of HMSN-SH, HMSN-SS-NH 2 , HMSN-SS-alkyne, DOX@HMSN-SS-CD and DOX@HMSN-SS-PLL(cit). 